\title{
Tunisian Toxoplasma gondii strains genotyping by the use of AK69 marker
}

\author{
Sonia Boughattas, Rym Ben-Abdallah, Emna Siala, Imen Ben-Abda, Olfa Souissi, Karim Aoun and Aida Bouratbine*
}

\begin{abstract}
Background: Clinical manifestation due to infection by Toxoplasma gondii is closely linked to the infecting strain of the parasite. Several genetic markers are available to determinate its genotype but few of them are able to discriminate between the three predominant lineages, namely types I, II and III. The number of markers decreases when atypical, recombinant/mixed genotypes need to be identified.

Findings: In our study, the contribution of sequence polymorphisms in the AK69 gene as typing markers for $T$. gondii was investigated for the first time in an epidemiological study. The coding region of the marker was amplified, sequenced and aligned for different Toxoplasma strains. The identified nucleotide polymorphism at 12 positions was able to highly discriminate between the different congenital toxoplasmosis Tunisian strains. Moreover the high detection sensitivity level of the marker enabled unambiguous identification of mixed/recombinant genotypes directly.

Conclusion: It can be, thus, very useful for direct typing in areas where such genotypes are frequently encountered, mainly in the African continent.
\end{abstract}

Keywords: AK69, high sensitivity, mixed genotype, Toxoplasma

\section{Findings}

Toxoplasma gondii ( $T$. gondii) is an intracellular protozoan that infects all warm-blooded animals including humans. It is considered as one of the most widespread parasites in the world [1]. While three genetic lineages I, II and III are predominant in Europe and North America [2], recombinant strains, are rather more frequently observed in North Africa [3].

Different methods are used for genotypic characterization of T.gondii $[4,5]$. A collection of more than 200 markers, allowing direct genotyping, was described [6]. Nevertheless most of them are biallelic and could distinguish just two of the 3 clonal types at a single locus. Only a small percentage of markers presents two biallelic polymorphisms that lie closely by each other and are able to identify even recombinant strains. AK69, one of these markers, located on chromosome $\mathrm{X}$, is the only one supposed to distinguish between the different types using a single restriction enzyme [6].

\footnotetext{
* Correspondence: aidabouratbine@pasteur.rns.tn

Laboratoire de Recherche 05SP03, Laboratoire de Parasitologie, Institut Pasteur de Tunis, 13 Place Pasteur BP74, Tunis Belvédères 1002, Tunisia
}

The aim of this study is to investigate the AK69 marker performance and contribution to the direct characterization of recombinant strains in Tunisia.

This study included 3 reference strains: RH (Type I), PRU (Type II) and NED (Type III) provided by CRB Toxoplasma (France) and 14 clinical specimens (11 Amniotic Fluids, 2 Placentas and 1 new born Cerebral Spinal Fluid) isolated from confirmed congenital toxoplasmosis cases [3]. These isolates were characterized previously by multilocus analysis at six polymorphic markers [3].

DDesigned primers were used in a PCR assay to amplify the polymorphic region of AK69 gene. AK69Fex TTGAACATCTGGTGCGAGAC and AK69Rex GTCTC CCAACCACCTCCATA were used as external primers and AK69F ACGAGCAACCATATCTTACC and AK69R CGAACGGACAACAAGCTA as internal ones. The annealing temperature was of $55^{\circ} \mathrm{C}$ for the first round amplification and $58^{\circ} \mathrm{C}$ for the second amplification round. A starting 1:100 dilution of primary PCR products was necessary for the second amplification round. Reaction was carried out in a final volume of 25 $\mu \mathrm{l}$ as described elsewhere [3]. 
PCR products were purified by GenElute PCR CleanUp Kit (Sigma Aldrich), and directly sequenced by Applied Biosystems 3130 Genetic Analyzer. Both forward and reverse PCR internal primers were used for the sequence reactions. SNPs have been identified, once sequences aligned.

The AK69 amplified products were also systematically digested with HinfI as recommended by the supplier (Invitrogen). The restriction fragments polymorphism within the locus was resolved by $3 \%$ agarose gel, stained with ethidium bromide and visualised under UV.

To test the sensitivity of the marker, control RH strain DNA was quantified by spectrometric method at the wave length of $260 \mathrm{~nm}$ and then diluted into aliquots from $100 \mathrm{ng}$ to $1 \mathrm{fg}$ using 1:10 dilutions. One microliter of each concentration was used in the PCR assay.

The amplified DNA by AK69 external primers gave a product of 633 base pairs. Small DNA amounts or no amplification products were detected after the first amplification round. The external primers were used simultaneity with other primers in our multiplex assay [3].

In the second round of amplification, positive reaction was obtained from all positive tested samples producing a 490 bp band. Negative controls (Water, Extracted no DNA, Negative sample) remained free of amplified products.

To test the sensitivity of the PCR assay, different quantities of $T$. gondii DNA were used. Analysis of the serial dilutions of $T$. gondii RH pure genomic DNA established a detection limit of the PCR assay at $100 \mathrm{fg}$.

Sequences analysis of the three reference strains [GenBank : HM003613, HM003614 and HM003615] showed several closely spaced polymorphisms by the presence of 12 substitutions nucleotide (at the positions 111, 125, $142,155,195,215,221,250,291,324,326$ and 378) resulting in three-way typing. It reveals four, one and two HinfI restriction sites for type I, II and III respectively.

The differential RFLP patterns visualized on the gel confirmed sequencing results and allowed easy and unambiguous discrimination of the three strains.

The restriction patterns analysis of AK69 for 13 clinical samples was unequivocal: two samples had type I allele (AF06/06, AF44/05), two others had type II allele (AF10/08, AF16/07) and three samples type III allele (CSF01/08, AF08/08, AF07/06). Five of the remaining strains revealed mixed profiles between two types: three strains (AF26/04, AF08/06, and AF33/05) were typed I/ III, two strains (PL05/06, AF19/04) typed I/II and one strain (PL04/06) was typed II/III. These results have been confirmed by direct sequencing of the PCR products: the SNPs of the corresponding two types were superposed on the same sequence [GenBank: JN82707, JN82708, JN82709 respectively] (Figure 1). The fourteenth isolate AF07/02 shows after restriction unique profile (u-1) including the common band of 199 bp and unusual one of approximately $270 \mathrm{bp}$. The corresponding sequence [GenBank: HM003616] revealed just two restriction HinfI sites at 199 and 221 positions suggesting thus the concomitant presence of type I and II. These results are in concordance with previous multilocus typing of the clinical samples (Table 1).

We report the first use of AK69 marker in an epidemiological study. Very little is known about this marker: its chromosomic location and abbreviation which was suggesting its putative function: adenosine kinase, despite the fact it was described for the first time in 2005 during the genome map realization of the Toxoplasma gondii [6]. Isolates previously studied were typed to individual level without ambiguity by this three-way marker. The results were in perfect agreement with the previous multilocus DNA analysis with regard to the power of identifying and differentiating these isolates. Indeed, the use of this marker in typing Tunisian strains revealed an interesting approach as it allowed solely, direct identification of final genotype in the half of the cases which is higher than other marker's rate (Table 1). In the other cases, it detected just one of the corresponding allele. Its ability to be used in a multiplex PCR reaction [3] is a significant advantage since the rate of identification of the final genotype exceeds $70 \%$ with the supplementary use of GRA6 marker and reaches 100\% with the use of SAG3 marker concerning Tunisian isolates. Our strains were typed to individual level without ambiguity by these three markers summarizing thus the result obtained by a 7 locus analysis.

Our results showed that the AK69 marker offers a new tool for direct identification of strains with promising alternative for recombinant ones even the small sample size which is explained by the low rate of the parasite detection during pregnancy in our country (these samples were retained positive from 243 analyzed specimens). Despite this, the performance of the AK69 marker could be very helpful especially in geographic areas with frequent mixed/recombinant strains like Africa continent [3]. Its use in a multiplex PCR reaction presents a further considerable advantage.

In addition, the detection limit of AK69 marker was shown to be $100 \mathrm{fg}$ of pure toxoplasmic DNA, which corresponds to one T. gondii organism [7]. AK69 gene marker was thus revealed to be the most sensitive described RFLP marker since it is more sensitive that SAG3 marker: detection limit 1 versus 5 to 10 parasite [4], making it more suitable to clinical samples with low parasite load.

Moreover the Blast X of our sequences demonstrated a perfect match with putative ROP8 protein. This rhoptry antigen belongs to ROP2 family [8]. This later is 


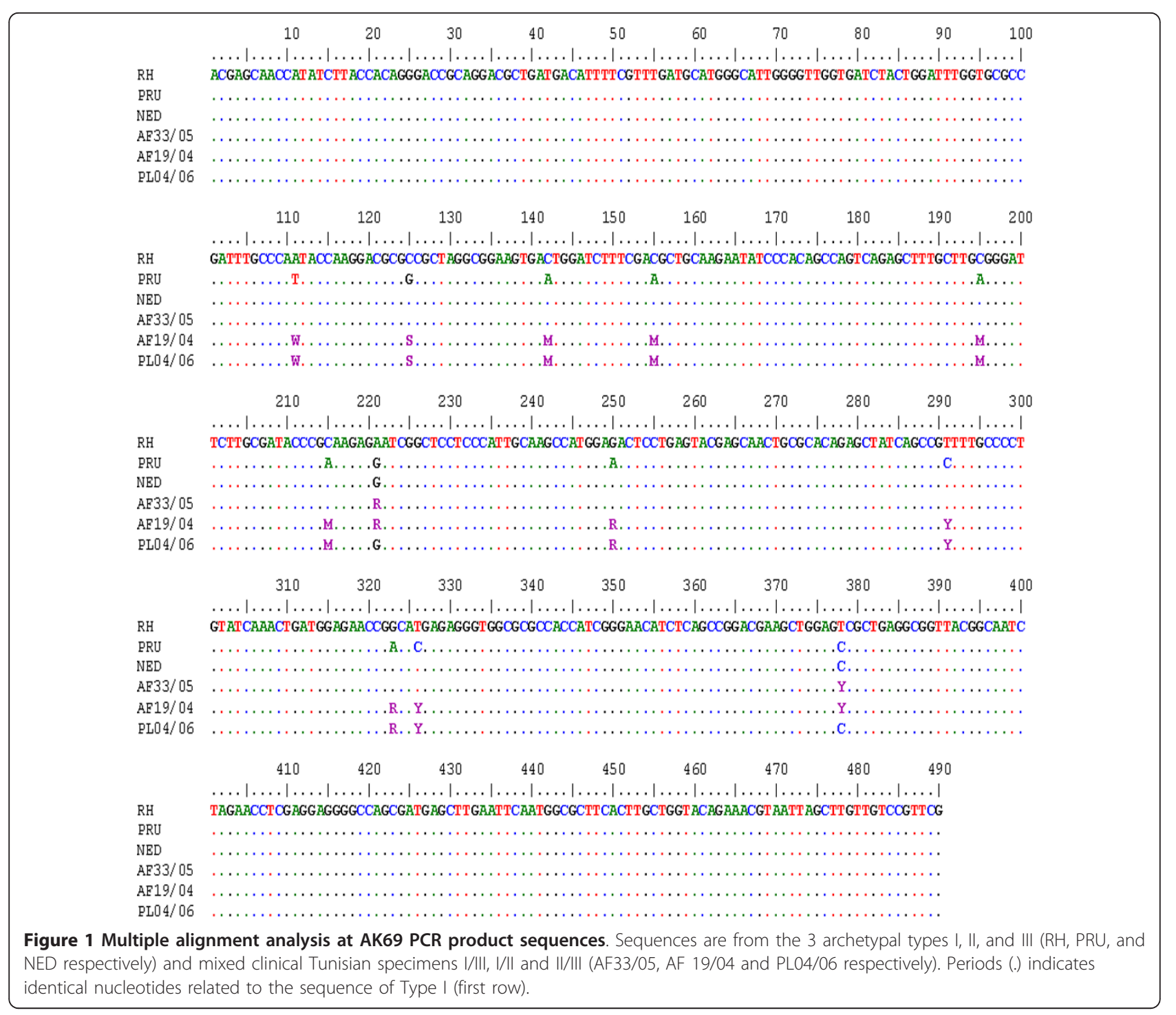

Table 1 Summary of AK69 genotyping results and previous multilocus typing of Tunisian clinical strains

\begin{tabular}{|c|c|c|c|c|c|c|c|c|}
\hline \multirow[b]{2}{*}{ Samples } & \multicolumn{8}{|c|}{ Alleles } \\
\hline & AK69 & 3'SAG2 & 5'SAG2 & SAG3 & GRA6 & BTUB & APICO & FINAL \\
\hline AF06/06 & 1 & 1 & 1 & 1 & 1 & 1 & 1 & 1 \\
\hline AF44/05 & 1 & 1 & 1 & 3 & 1 & 1 & 1 & $|/|||$ \\
\hline CSF01/08 & 3 & 1 & 1 & 3 & 1 & 1 & 1 & $|/|||$ \\
\hline AF08/08 & 3 & 1 & 1 & 3 & 1 & 1 & 1 & $|/|||$ \\
\hline AF26/04 & $1+3$ & 1 & 1 & 3 & 1 & 3 & 1 & $|/|||$ \\
\hline AF08/06 & $1+3$ & 1 & 1 & 3 & 1 & 3 & 3 & $|/|||$ \\
\hline AF33/05 & $1+3$ & 1 & 1 & $1+3$ & 1 & 3 & 1 & $|/|||$ \\
\hline AF07/06 & 3 & 1 & 1 & 3 & $1+3$ & 1 & 1 & $|/|||$ \\
\hline PL05/06 & $1+2$ & 1 & 1 & 2 & $1+2$ & ND & 1 & $|/| \mid$ \\
\hline AF07/02 & $1+2$ & 1 & 1 & ND & $1+2$ & $1+2$ & 1 & $|/| \mid$ \\
\hline AF19/04 & $1+2$ & 1 & 1 & $1+2$ & $1+2$ & $1+2$ & 1 & $|/| \mid$ \\
\hline PL04/06 & $2+3$ & 1 & 1 & $2+3$ & 1 & ND & 1 & $|/||/|||$ \\
\hline AF10/08 & 2 & 1 & 1 & $2+3$ & 1 & ND & 1 & $|/||/|||$ \\
\hline AF16/07 & 2 & 1 & 1 & $1+2+3$ & 1 & ND & 1 & $|/||/|||$ \\
\hline
\end{tabular}


known as a major virulence component and is involved during the invasion process of host cells as well as crucial biological functions [9].

\section{Conclusion}

The molecular approaches presented in our work offer an easy and a highly sensitive discrimination of the different $T$. gondii strains even in presence of mixed or new types. A potential implication of this marker in virulence pathway is also suggested.

\section{Acknowledgements}

This study was supported by the Ministry of Higher Education, Research and Technology in Tunisia and carried out within the framework of the Research Lab "Parasitoses emergentes" LR 05SP03.

\section{Authors' contributions}

SB carried out the molecular studies, the sequence alignment and drafted the manuscript. RBA and ES have made substantial contributions to acquisition of data and their analysis. IBA have been involved in drafting the manuscript and revised the English typing. OS carried out qPCR for diagnosis. KA has been involved in revising the manuscript critically for important intellectual content. $\mathrm{AB}$ conceived the study and has given financial support. All authors approved the final version of the manuscript.

\section{Competing interests}

No conflict interest is declared.

Received: 25 July 2011 Accepted: 26 August 2011

Published: 26 August 2011

\section{References}

1. Webster Joanne P: Review of "Toxoplasmosis of Animals and Humans (Second Edition)" by J.P. Dubey. Parasites \& Vectors 2010, 3:112.

2. Howe DK, Sibley LD: Toxoplasma gondii comprises three clonal lineages: correlation of parasite genotype with human disease. J Infect Dis 1995, 172:1561-1566.

3. Boughattas S, Ben-Abdallah R, Siala E, Souissi O, Aoun K, Bouratbine A: Direct genotypic characterization of Toxoplasma gondii strains associated with congenital toxoplasmosis in Tunisia (North Africa). Am J Trop Med Hyg 2010, 82:1041-1046.

4. Khan A, Su C, German M, Storch GA, Clifford DB, Sibley LD: Genotyping of Toxoplasma gondii strains from immunocompromised patients reveals high prevalence of type I strains. J Clin Microbiol 2005, 43:5881-5887.

5. Ajzenberg D, Dumètre A, Dardé ML: Multiplex PCR for typing strains of Toxoplasma gondii. I Clin Microbiol I 2005, 43:1940-1943.

6. Khan A, Taylor S, Su C, Mackey AJ, Boyle J, Cole R, Glover D, Tang K, Paulsen IT, Berriman M, Boothroyd JC, Pfefferkorn ER, Dubey JP, Ajioka JW, Roos DS, Wootton JC, Sibley LD: Composite genome map and recombination parameters derived from three archetypal lineages of Toxoplasma gondii. Nucleic Acids Res 2005, 33:2980-2982.

7. Cornelissen AW, Overdulve JP, van der Ploeg M: Determination of nuclear DNA of five eucoccidian parasites, Isospora (Toxoplasma) gondii, Sarcocystis cruzi, Eimeria tenella, E. acervulina and Plasmodium berghei, with special reference to gamontogenesis and meiosis in I. (T.) gondii. Parasitology 1984, 88:531-553.

8. Bradley PJ, Ward C, Cheng SJ, Alexander DL, Coller S, Coombs GH, Dunn JD, Ferguson DJ, Sanderson SJ, Wastling JM, Boothroyd JC: Proteomic analysis of rhoptry organelles reveals many novel constituents for host-parasite interactions in Toxoplasma gondii. J Biol Chem 2005, 280:34245-34258.

9. Dlugonska H: Toxoplasma rhoptries: unique secretory organelles and source of promising vaccine proteins for immunoprevention of toxoplasmosis. J Biomed Biotechno 2008, 2008:632-424.

doi:10.1186/1756-3305-4-167

Cite this article as: Boughattas et al.: Tunisian Toxoplasma gondii strains genotyping by the use of AK69 marker. Parasites \& Vectors 2011 4:167.

\section{Submit your next manuscript to BioMed Central and take full advantage of:}

- Convenient online submission

- Thorough peer review

- No space constraints or color figure charges

- Immediate publication on acceptance

- Inclusion in PubMed, CAS, Scopus and Google Scholar

- Research which is freely available for redistribution

Submit your manuscript at www.biomedcentral.com/submit
C Biomed Central 